\title{
Cutting Forces in Milling of Carbon Fibre Reinforced Plastics
}

\author{
Luca Sorrentino and Sandro Turchetta \\ Department of Civil and Mechanical Engineering, University of Cassino and Southern Lazio, 03043 Cassino, Italy \\ Correspondence should be addressed to Luca Sorrentino; sorrentino@unicas.it
}

Received 9 July 2014; Revised 16 October 2014; Accepted 17 October 2014; Published 13 November 2014

Academic Editor: Thomas R. Kurfess

Copyright (C) 2014 L. Sorrentino and S. Turchetta. This is an open access article distributed under the Creative Commons Attribution License, which permits unrestricted use, distribution, and reproduction in any medium, provided the original work is properly cited.

\begin{abstract}
The machining of fibre reinforced composites is an important activity for optimal application of these advanced materials into engineering fields. During machining any excessive cutting forces have to be avoided in order to prevent any waste product in the last stages of production cycle. Therefore, the ability to predict the cutting forces is essential to select process parameters necessary for an optimal machining. In this paper the effect of cutting conditions during milling machining on cutting force and surface roughness has been investigated. In particular the cutting force components have been analysed in function of the principal process parameters and of the contact angle. This work proposes experimental models for the determination of cutting force components for CFRP milling.
\end{abstract}

\section{Introduction}

Composite materials milling is a rather complex task owing to its heterogeneity and some problems such as surface delamination appearing during the machining process, associated with the characteristics of the material and cutting parameters.

Milling is the machining operation most frequently used in manufacturing of fibre reinforced plastics parts as a corrective operation to produce well-defined and high-quality surfaces that often require the removal of excess material to control tolerances [1]. The machinability of fibre reinforced plastics is strongly influenced by the type of fibre embedded in the composite and by its properties. Mechanical and thermal properties have an extreme importance in machining FRP. The fibre used in the composites has a great influence in the selection of cutting tools (cutting edge material and geometry) and machining parameters. It is fundamental to ensure that the tool selected is suitable for the material. The knowledge of cutting mechanisms is necessary to optimize the cutting mechanics and machinability in milling $[1,2]$. Composite materials such as carbon fibre reinforced plastics (CFRPs) made by using carbon fibres for reinforcing plastic resin matrices, such as epoxy, are characterised by excellent properties as light weight, high strength, and high stiffness. These properties make them especially attractive for aerospace applications [2]. Surface roughness is a parameter that has a great influence on dimensional precision, on performance of mechanical pieces, and on production costs. For these reasons, research developments have been carried out with the purpose of optimising the cutting conditions to reach a specific surface roughness $[3,4]$. The required quality of the machined surface depends on the mechanisms of material removal and the kinetics of machining processes affecting the performance of the cutting tools [5]. The works of a number of authors [6-12], when reporting on milling of FRP, show that the type and orientation of the fibre, cutting parameters, and tool geometry have an essential influence on the machinability. Everstine and Rogers [6] have presented the first theoretical work on the machining of FRPs in 1971, since then the research carried out in this area has been based on experimental investigations. Koplev et al. [7], Kaneeda [8], and Puw and Hocheng [9] established that the principal cutting mechanisms are strongly correlated to fibre arrangement and tool geometry. Santhanakrishnan et al. [10] and Ramulu et al. [11] carried out a study on machining of polymeric composites and concluded that an increasing of the cutting speed leads to a better surface finish. Hocheng et al. 
[12] studied the effect of the fibre orientation on the cut quality, cutting forces, and tool wear on the machinability. Hintze Wolfgang et al. [13] investigated the case of delamination of the top layers during the machining of CFRP tape milling and have showed that delamination depends highly on the fibre orientation and the tool sharpness.

Liu et al. [14] summarized an up-to-date progress in mechanical drilling of composite laminates reported in the literature; they cover drilling operations (including conventional drilling, grinding drilling, vibration-assisted twist drilling, and high speed drilling), drill bit geometry and materials, drilling-induced delamination and its suppressing approaches, thrust force, and tool wear.

Enemuoh et al. [15] realized that, with the application of the technique of Taguchi and a multiobjective optimization criterion, it is possible to achieve cutting parameters that allow the absence of damage in drilling of fibre reinforced plastics. Davim et al. [16] studied the cutting parameters (cutting velocity and feed rate) under specific cutting pressure, thrust force, damage, and surface roughness in drilling glass fibre reinforced plastics (GFRPs). A plan of experiments, based on the techniques of Taguchi, was established considering drilling with prefixed cutting parameters in a hand lay-up GFRP material. Sheikh-Ahmad et al. [17] studied the comprehensive model for orthogonal milling of unidirectional composites at various fibre orientations. Kalla et al. [18] studied the mechanistic modelling techniques for simulating the cutting of carbon fibre reinforced polymers (CFRPs) with a helical end mill. A methodology was developed for predicting the cutting forces by transforming specific cutting energies from orthogonal cutting to oblique cutting.

Yashiro et al. [19] confirmed that the measurement of the cutting temperature is important when dealing with CFRP: temperatures higher than the glass-transition temperature of the matrix resin are not favourable as they damage the laminate. In Liu et al. [20] a heat transfer model is developed to investigate the temperature distribution of CFRP workpiece in helical milling process. The relationship between cutting speed and temperature of processing is pointed out. In summary, it can be noticed that the works carried out on the machinability of FRP are basically related to the wear of cutting tools and the quality of the surfaces, as a function of the cutting conditions, the distribution, and angle of inclination of fibres in the polymeric matrix.

The aim of this work is to value cutting forces of carbon fibre reinforced plastics during the milling machining. This work aims to investigate the relationship among the cutting force and the surface finishing of machined laminate as a function of relevant cutting parameters, such as the cutting speed, axial depth of cut, and the feed rate. In particular, the most interesting machining conditions from an industrial point of view have been investigated in order to measure the cutting force components by a dynamometer. The obtained values of cutting force have been put into relationship with the angular position of the cutter. In the following the models of the relationship between cutting force, chip thickness, and process parameters have been presented.

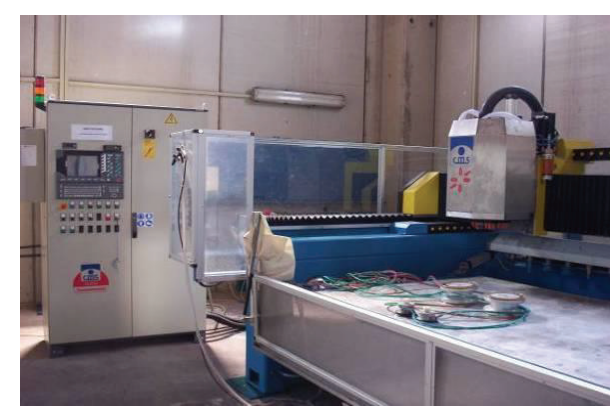

FIGURE 1: CNC milling machine.

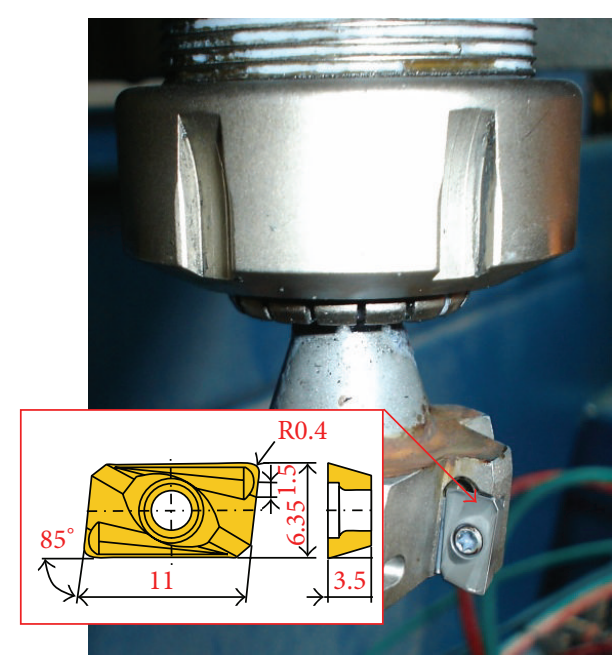

FIGURE 2: End mill with a single cutting tooth (MITSUBISHI).

\section{Experimental Setup}

The experiments have been undertaken on a CNC milling machine with $15 \mathrm{~kW}$ spindle power where maximum spindle speed of $15000 \mathrm{rpm}$ has been used to perform the experiments; see Figure 1. An end mill commonly used for the machining of CFRP has been used, whose diameter is $40 \mathrm{~mm}$, with a single cutting tooth (insert APMT1135PDERH1 UTi20T of MITSUBISHI); see Figure 2. The composite material used in the tests (epoxy matrix reinforced with 50\% of carbon fibre) has been produced by autoclave with a fibre orientation of $0 / 90^{\circ}$. The experiments have been carried out in a laminate plate, made up with 40 alternating layers of fibres with $13 \mathrm{~mm}$ of thickness; the tests have been carried out by up-milling, in the absence of cooling fluid. In Figure 3 the surface machined can be observed: machining (a) has been performed with the aim of realizing the correct tool access for the following machining: (b), (c), and (d).

Three cutting speed values, four axial cutting depth values, and two feeds per tooth per revolution have been taken into account; they have been chosen in order to reproduce the commonly used industrial range of process variables. Each cut has been replicated three times, yielding a total of 72 measured forces. The plan of experiments is shown in Table 1. The cutting conditions have been represented by the angular position of the cutter $(\theta)$. The experimental cuts have been 


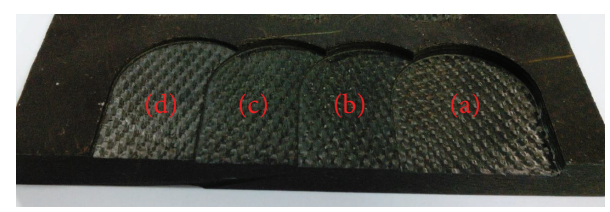

FIGURE 3: Sample after milling machining.

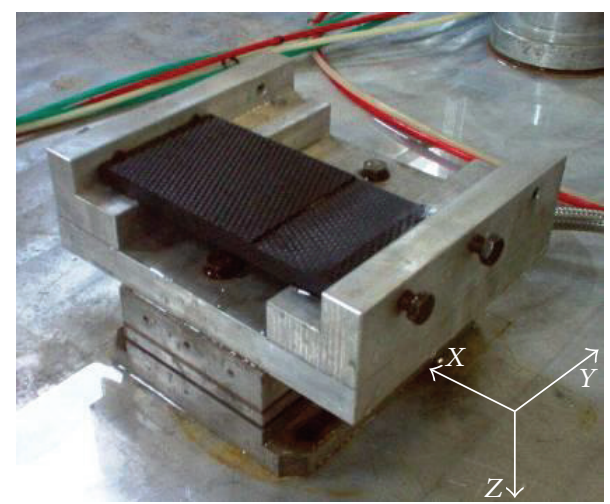

FIGURE 4: Gripping system/dynamometer/sample.

TABLE 1: Experimental plan.

\begin{tabular}{lcc}
\hline Factors & Levels [\#] & Value \\
\hline$p_{a}$, axial cutting depth $[\mathrm{mm}]$ & 4 & $1.0-1.5-2.0-3.0$ \\
$p_{r}$, radial cutting depth $[\mathrm{mm}]$ & 1 & 25 \\
$V_{t}$, cutting speed $[\mathrm{m} / \mathrm{min}]$ & 3 & $100-200-300$ \\
$f_{t}$, feed per tooth $[\mathrm{mm}]$ & 2 & $0.022-0.044$ \\
\hline Replications & 3 & \\
Total cuts & 72 & \\
\hline
\end{tabular}

performed in a random sequence, in order to reduce the effect of any possible systematic error. The cutting forces $F_{x}$ and $F_{y}$ have been measured by a Kistler piezoelectric platform dynamometer (type $9257 \mathrm{BA}$ ); see Figure 4. The signals acquired by the dynamometer have been sampled at different frequencies and for different time intervals in order to set the acquisition parameters giving the whole information about force signal with the minimum time waste. The signal along $X$ and $Y$ axes is periodic and 16384 acquisition points seem to be enough to keep the whole signal information. Therefore, the output of the dynamometer has been fed into an A/D converter and sampled at $10 \mathrm{kHz}$ by a PC. Each observation consisted of about $1.6384 \mathrm{~s}$ time signal $[21,22]$.

The typical force signals acquired by dynamometer along $X$ and $Y$ axes, respectively, have been reported in Figures 5, 6 , and 7 . In Figure 8 the signal acquired by dynamometer for 8 tool's round is shown. The acquired signal is time periodic; in Figure 9 only one period is shown.

The tangential $F_{T}$ and radial $F_{R}$ components of the cutting force have been calculated according to (1) (see Figure 10):

$$
\begin{aligned}
& F_{T}=F_{y} \cos \theta-F_{x} \sin \theta, \\
& F_{R}=F_{x} \cos \theta+F_{y} \sin \theta .
\end{aligned}
$$

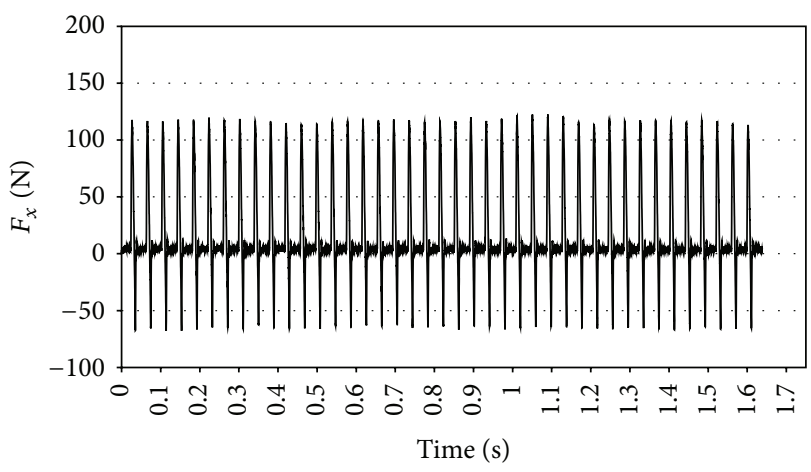

FIGURE 5: Example of time domain signal monitored in $X$ direction.

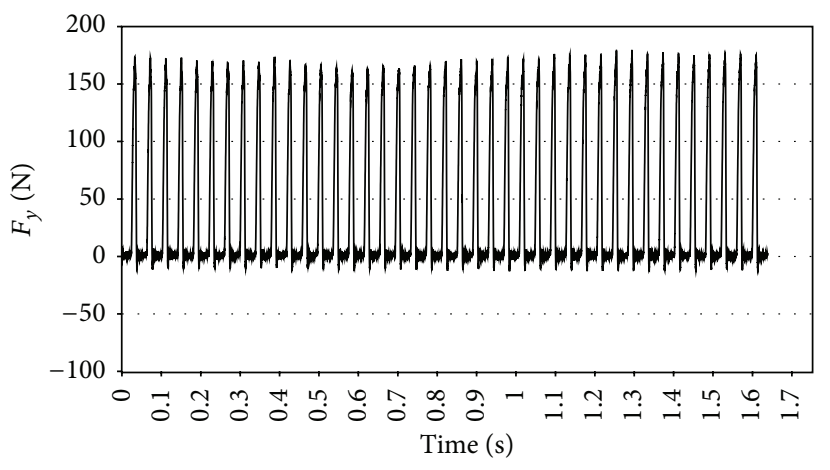

FIGURE 6: Example of time domain signal monitored in $Y$ direction.

\section{Results and Discussion: Forces Analysis}

Some preliminary tests have been carried out with fixed process parameters in order to verify the testing system stability and the repeatability of the test itself.

Cutting force components in tangential and normal direction have been calculated by acquiring force signal for each test. The signals have been analyzed in time domain as function of contact angle between $0^{\circ}$ and $90^{\circ}$. Since a similar trend of the forces for every tool round has been observed only the results for first round of the tool have been reported. The trends of tangential cutting force components as function of contact angle and cut depth have been reported in Figures 11, 12, and 13. Figure 11 reports tangential cutting force component as function of contact angle, obtained with a cutting speed of $100 \mathrm{~m} / \mathrm{min}$ and a tooth feed of $0.022 \mathrm{~mm}$; as it can be seen from the graph the cutting force tangential component increases with cut depth and with contact angle. In particular, with thin contact angles there is a fast force increase, while with angles near $90^{\circ}$ it is practically constant. Similar trends have been obtained with cutting speed of $200 \mathrm{~m} / \mathrm{min}$ and $300 \mathrm{~m} / \mathrm{min}$. Figure 12 reports tangential cutting force component versus contact angle obtained with a cutting speed of $200 \mathrm{~m} / \mathrm{min}$ and tooth feed of $0.022 \mathrm{~mm}$. Figure 13 reports tangential cutting force component versus contact angle obtained with a cutting speed of $300 \mathrm{~m} / \mathrm{min}$ and tooth feed of $0.022 \mathrm{~mm}$. The trends of radial cutting force component as function of contact angle and cut depth have 


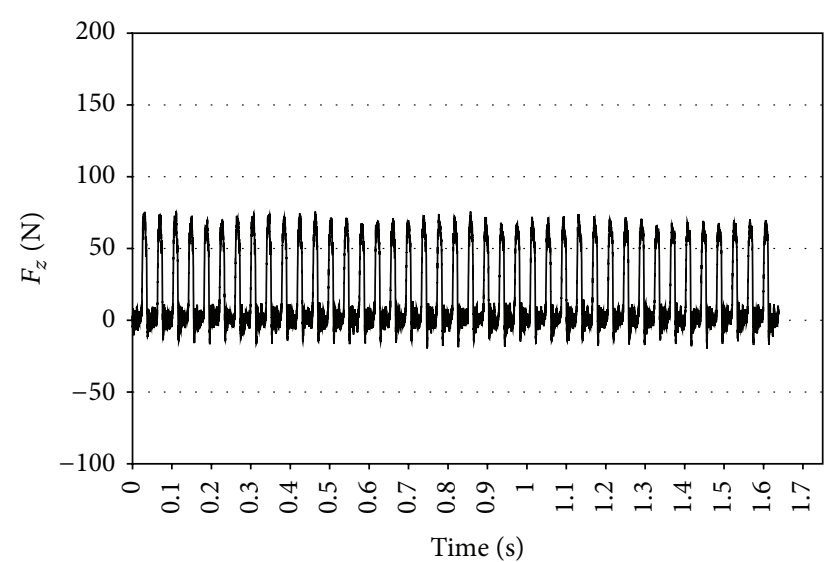

FIGURE 7: Example of time domain signal monitored in $Z$ direction.

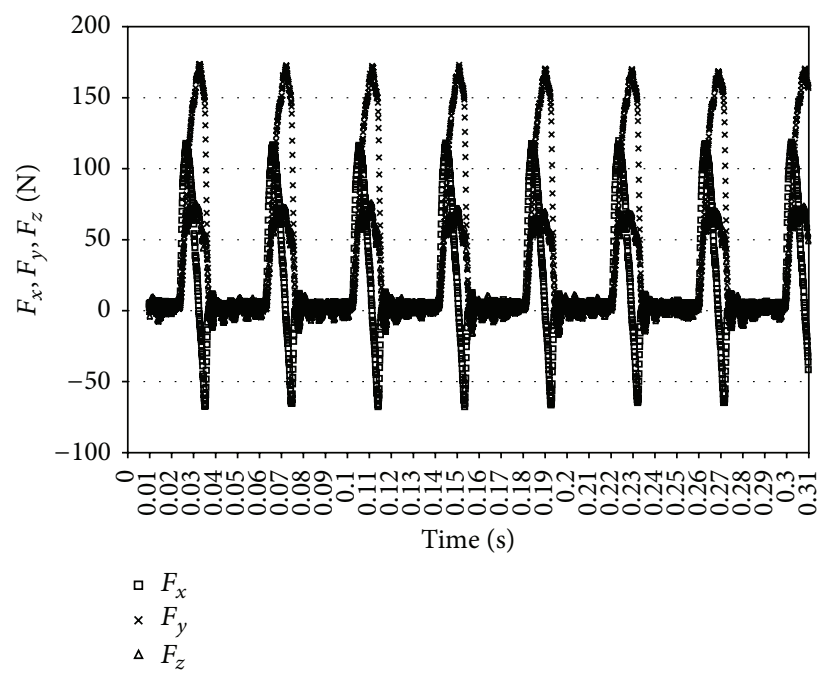

FIgure 8: Time domain signal monitored in $X, Y$, and $Z$ directions for eight tool's round.

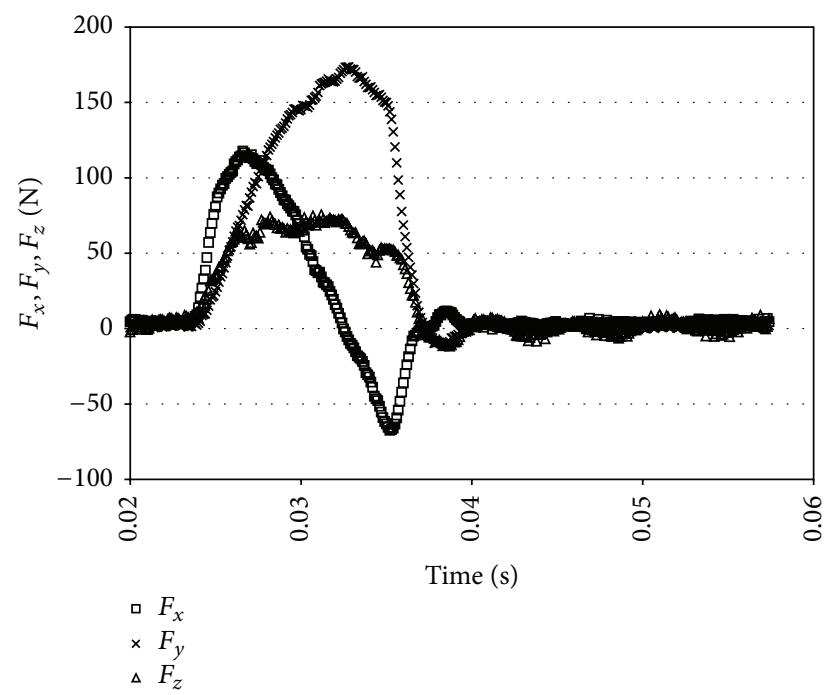

FIGURE 9: Time domain signal monitored in $X, Y$, and $Z$ directions for one tool's round.

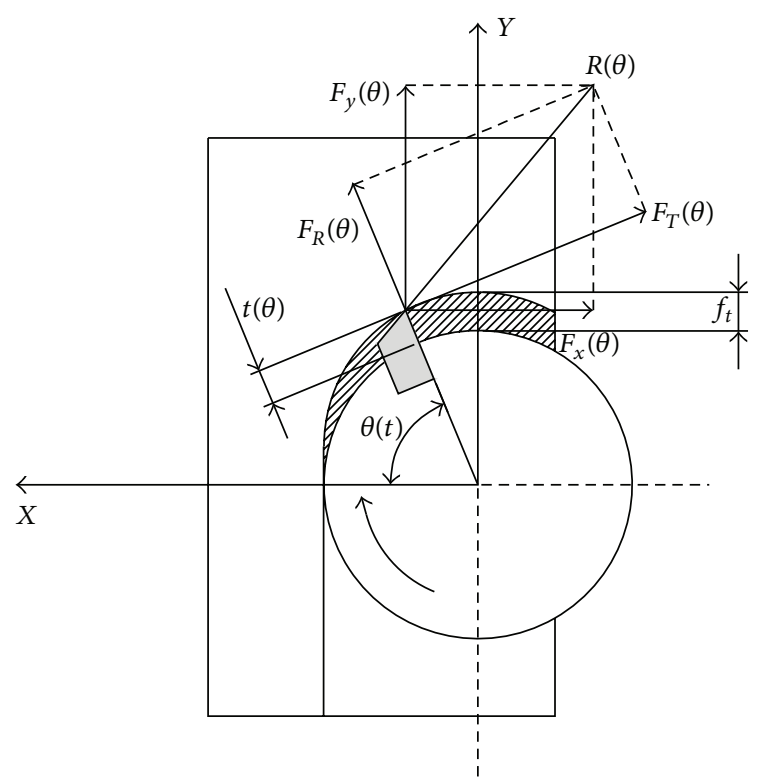

Figure 10: Scheme of $F_{T}$ and $F_{R}$ force components.

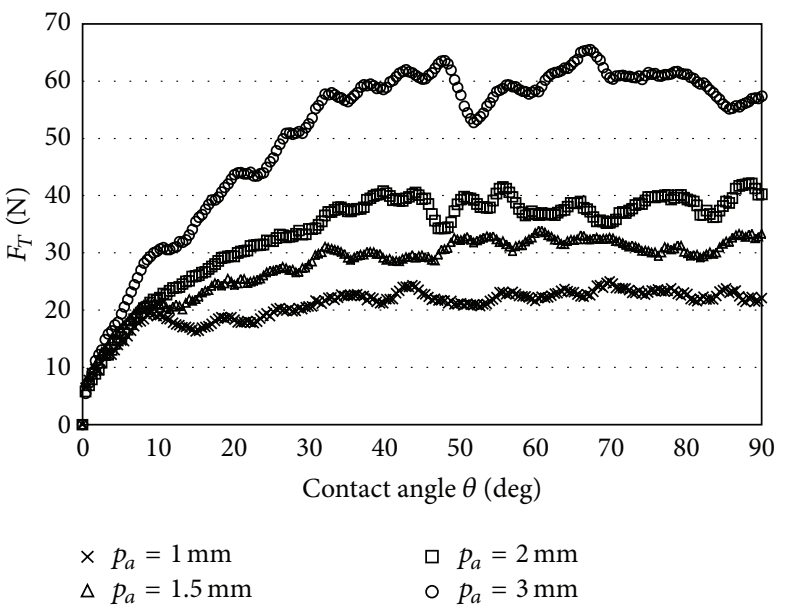

FIGURE 11: $F_{T}$ component versus contact angle (cutting speed $=$ $100 \mathrm{~m} / \mathrm{min}$; feed per tooth $=0.022 \mathrm{~mm}$ ).

been reported in Figures 14, 15, and 16. Figure 14 reports radial cutting force component versus contact angle obtained with a cutting speed of $100 \mathrm{~m} / \mathrm{min}$ and a tooth feed of $0.022 \mathrm{~mm}$. The cutting force radial component as the tangential cutting force component increases with cut depth and with contact angle. In particular, with thin contact angles there is a fast force increase, while with angles in range of $40^{\circ}-90^{\circ}$ it is practically constant. Similar trends have been obtained with cutting speed of $200 \mathrm{~m} / \mathrm{min}$ and $300 \mathrm{~m} / \mathrm{min}$.

Figure 15 reports radial cutting force component versus contact angle obtained with cutting speed of $200 \mathrm{~m} / \mathrm{min}$ and tooth feed of $0.022 \mathrm{~mm}$. Figure 16 reports radial cutting force component versus contact angle obtained with cutting speed of $300 \mathrm{~m} / \mathrm{min}$ and tooth feed of $0.022 \mathrm{~mm}$. Cutting tests carried out with a tooth feed of $0.044 \mathrm{~mm}$ have shown an increase of cutting force components and a trend, as 


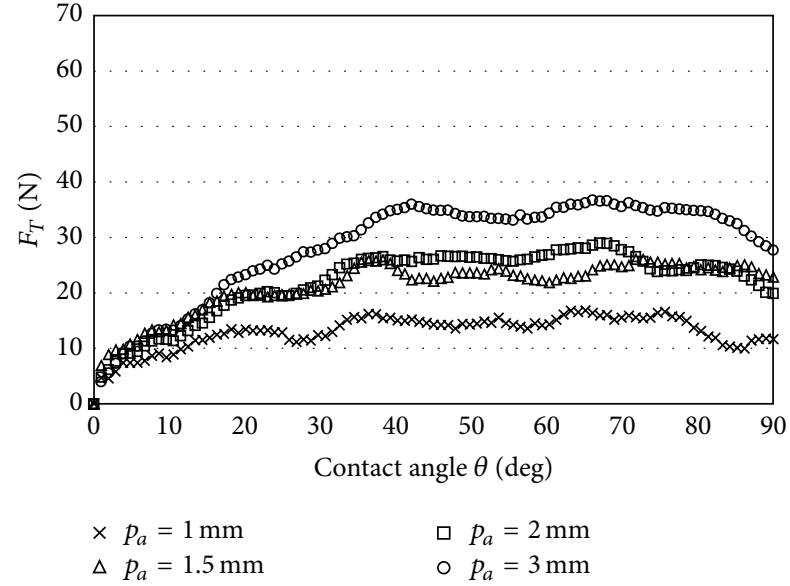

FIGURE 12: $F_{T}$ component versus contact angle (cutting speed = $200 \mathrm{~m} / \mathrm{min}$; feed per tooth $=0.022 \mathrm{~mm}$ ).

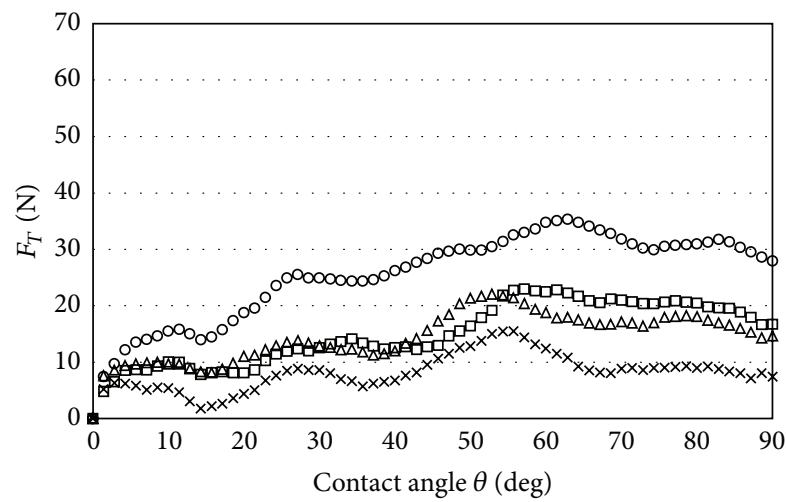
$\times p_{a}=1 \mathrm{~mm}$
$p_{a}=2 \mathrm{~mm}$
$\Delta p_{a}=1.5 \mathrm{~mm}$
○ $p_{a}=3 \mathrm{~mm}$

FIGURE 13: $F_{T}$ component versus contact angle (cutting speed $=$ $300 \mathrm{~m} / \mathrm{min}$; feed per tooth $=0.022 \mathrm{~mm}$ ).

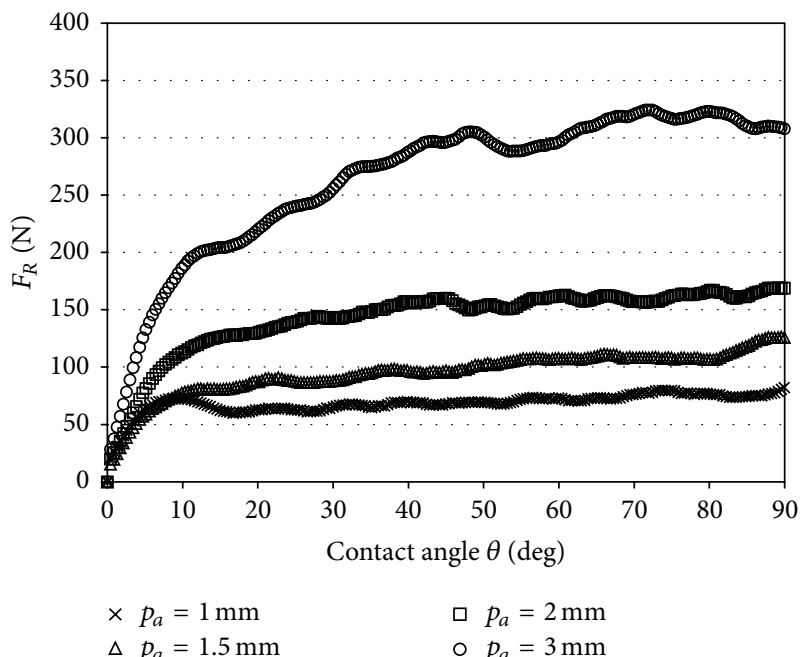

FIGURE 14: $F_{R}$ component versus contact angle (cutting speed = $100 \mathrm{~m} / \mathrm{min}$; feed per tooth $=0.022 \mathrm{~mm}$ ).

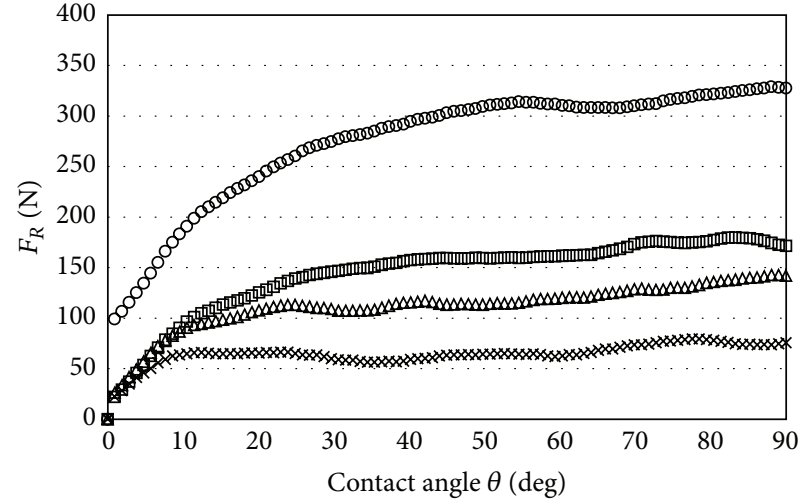
$\times p_{a}=1 \mathrm{~mm}$
ㅁ $p_{a}=2 \mathrm{~mm}$
$\Delta p_{a}=1.5 \mathrm{~mm}$
- $p_{a}=3 \mathrm{~mm}$

FIGURE 15: $F_{R}$ component versus contact angle (cutting speed = $200 \mathrm{~m} / \mathrm{min}$; feed per tooth $=0.022 \mathrm{~mm}$ ).

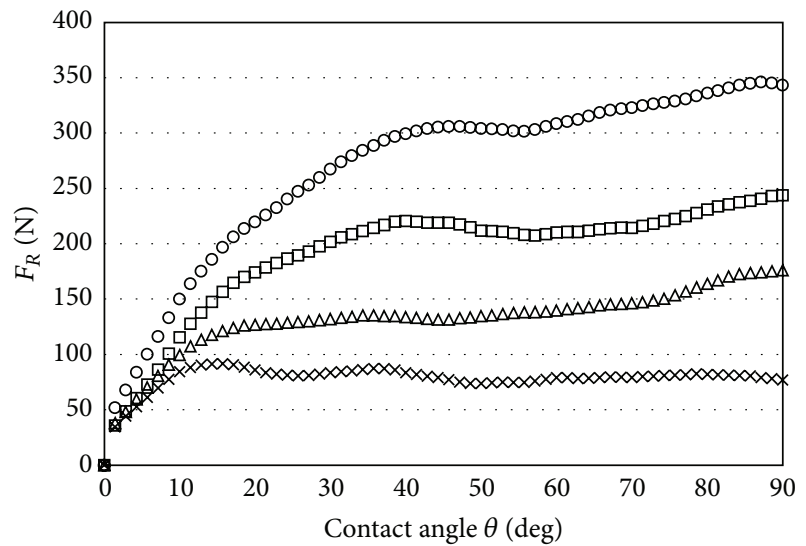
$\times p_{a}=1 \mathrm{~mm}$
ㅁ $p_{a}=2 \mathrm{~mm}$
$\Delta p_{a}=1.5 \mathrm{~mm}$
○ $p_{a}=3 \mathrm{~mm}$

FIGURE 16: $F_{R}$ component versus contact angle (cutting speed = $300 \mathrm{~m} / \mathrm{min}$; feed per tooth $=0.022 \mathrm{~mm}$ ).

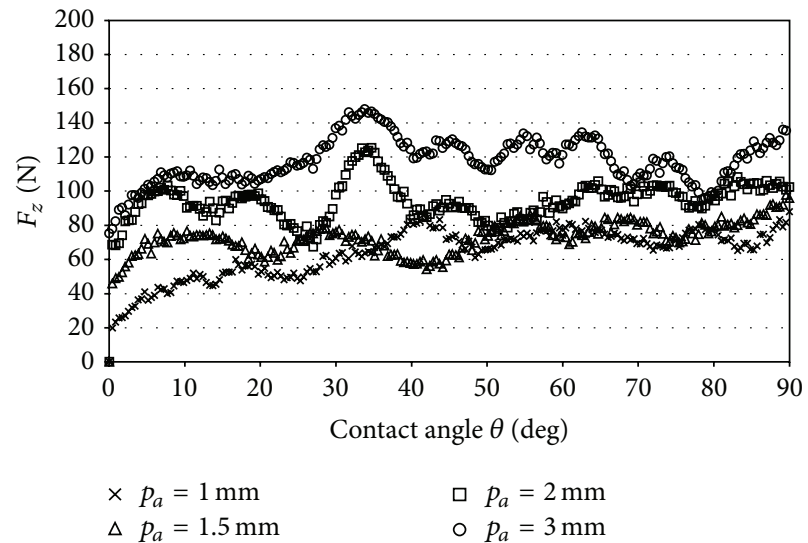

FIGURE 17: $F_{z}$ component versus contact angle (cutting speed = $100 \mathrm{~m} / \mathrm{min}$; feed per tooth $=0.044 \mathrm{~mm}$ ). 


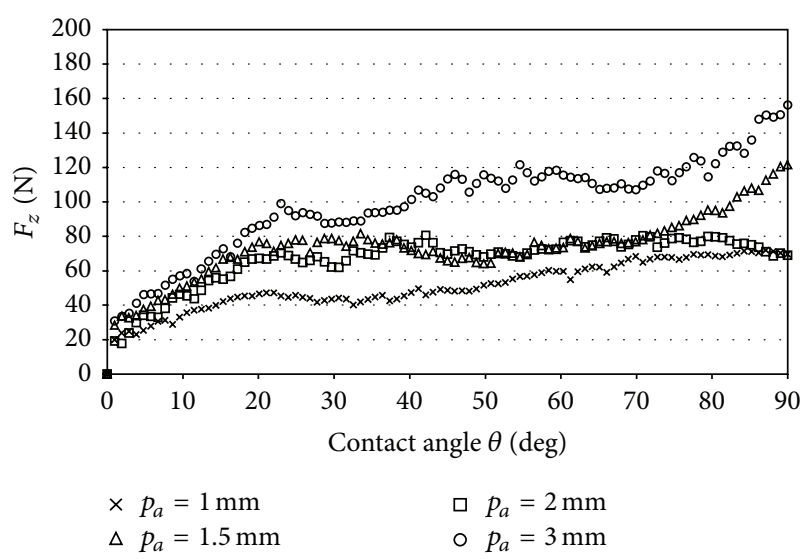

FIGURE 18: $F_{z}$ component versus contact angle (cutting speed $=$ $200 \mathrm{~m} / \mathrm{min}$; feed per tooth $=0.044 \mathrm{~mm}$ ).

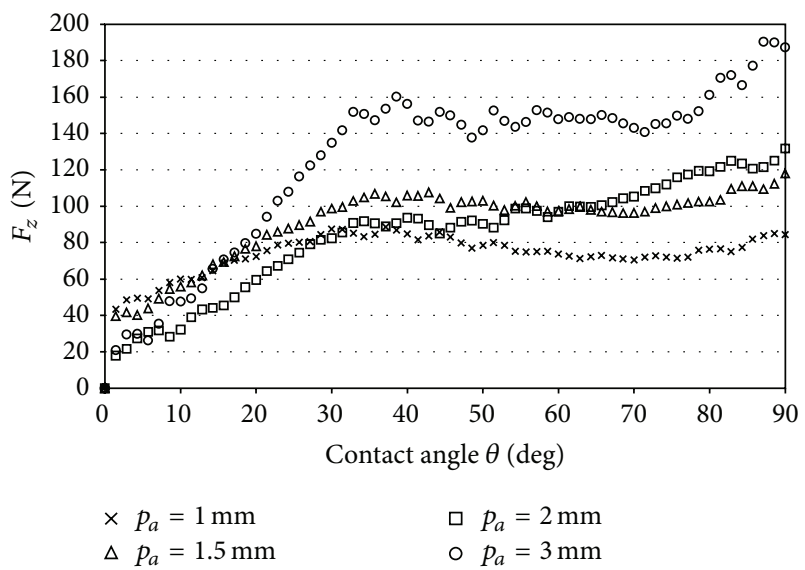

FIGURE 19: $F_{z}$ component versus contact angle (cutting speed = $300 \mathrm{~m} / \mathrm{min}$; feed per tooth $=0.044 \mathrm{~mm}$ ).

a function of contact angle and cut deep, similar to that one found with tooth feed of $0.022 \mathrm{~mm}$.

With particular regard to component $F_{T}$ of the cutting force, it decreases with increasing of the cutting speed; in fact, the maximum value of " $F_{T}$ " is $65 \mathrm{~N}$, in correspondence of $V_{t}=$ $100 \mathrm{~m} / \mathrm{min}$ and $p_{a}=3 \mathrm{~mm}$, and it is $38 \mathrm{~N}$, in correspondence of $V_{t}=300 \mathrm{~m} / \mathrm{min}$ and $p_{a}=3 \mathrm{~mm}$. This reduction does not result for force radial component " $F_{R}$ " which remains substantially constant as a function of cutting speed.

In Figures 17-19 the trends of component $F_{z}$ of the cutting force have been reported as a function of the process parameters considered. In particular, Figure 17 shows the trend of component $F_{z}$ in function of axial cutting depth " $p_{a}$ " relatively to the cutting speed of $100 \mathrm{~m} / \mathrm{min}$. From the graph it is possible to note that component $F_{z}$ increases rapidly with the increase of the contact angle to then assume almost a constant value. The maximum value of this force increases with the increase of axial cutting depth from about $60 \mathrm{~N}$ to $140 \mathrm{~N}$. Figures 18-19 show the trend of component $F_{z}$ in function of " $p$ a" relatively to the cutting speed of $200 \mathrm{~m} / \mathrm{min}$ and $300 \mathrm{~m} / \mathrm{min}$; the graphs show how by increasing $V_{t}$

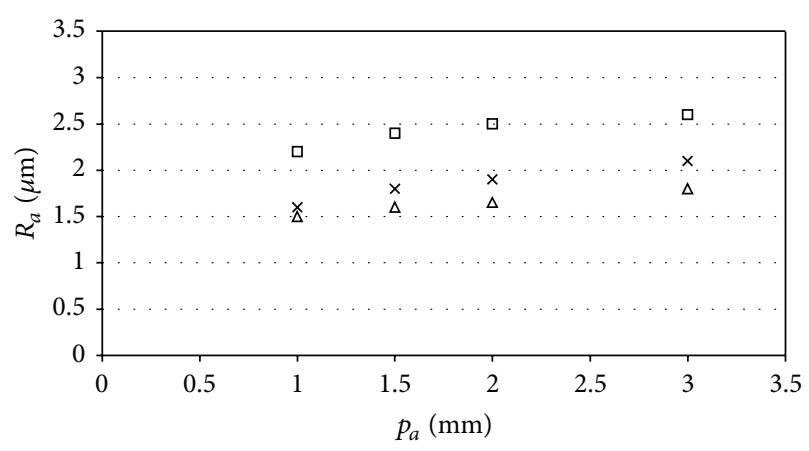

ㅁ $V_{t}=100 \mathrm{~m} / \mathrm{min}$

$\times V_{t}=200 \mathrm{~m} / \mathrm{min}$

$\Delta V_{t}=300 \mathrm{~m} / \mathrm{min}$

FIGURE 20: Surface roughness versus $p_{a}($ feed per tooth $=0.022)$.

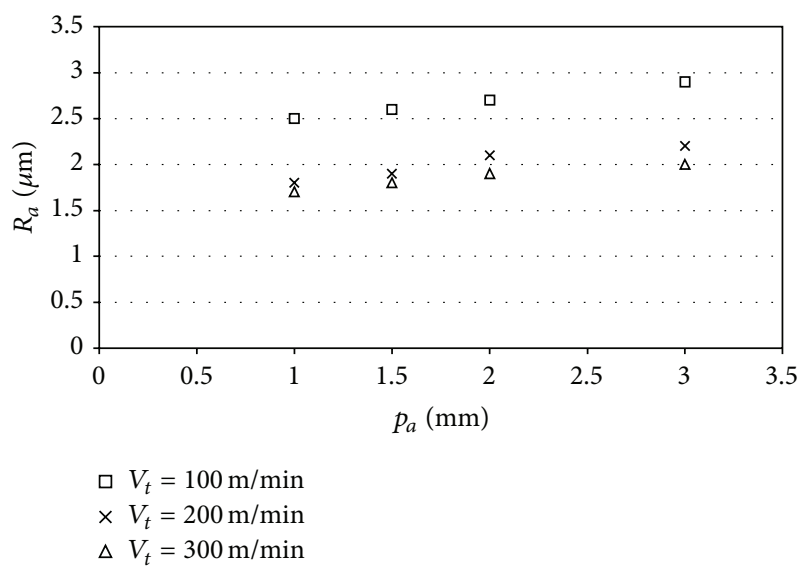

FIGURE 21: Surface roughness versus $p_{a}($ feed per tooth $=0.044)$.

TABLE 2: Constant values of the model.

\begin{tabular}{lccc}
\hline$K_{T}$ & $v_{T}$ & $\alpha_{T}$ & $\beta_{T}$ \\
\hline 2455.00 & 0.333 & 0.777 & -0.705 \\
\hline$K_{R}$ & $v_{R}$ & $\alpha_{R}$ & $\beta_{R}$ \\
\hline 83.17 & 0.262 & 1.190 & 0.191 \\
\hline
\end{tabular}

the values of component $F_{z}$ do not significantly change but the initial transient extends for a greater contact angle.

Regression analysis has allowed determining the model for evaluation of cutting force components shown in

$$
\begin{aligned}
& F_{T}=K_{T} \cdot t_{\theta}^{v_{T}} \cdot p_{a}^{\alpha_{T}} \cdot V_{T}^{\beta_{T}}, \\
& F_{R}=K_{R} \cdot t_{\theta}^{v_{R}} \cdot p_{a}^{\alpha_{R}} \cdot V_{T}^{\beta_{R}}
\end{aligned}
$$

with $t_{\theta}=f_{t} \sin \theta$.

The values of regression model constants are reported in Table 2. The coefficients of determination are higher than $95 \%$, while the hypotheses (normality and homogeneity of variance) about the residuals are satisfied. 


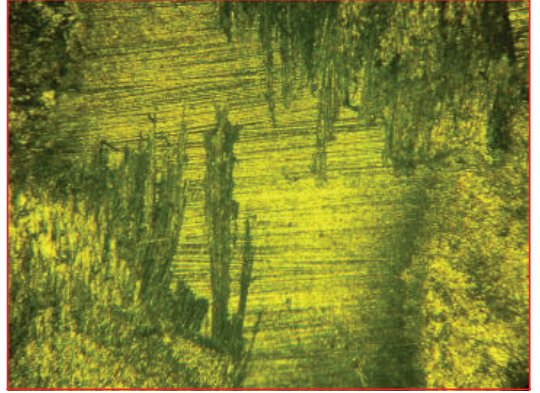

(a)

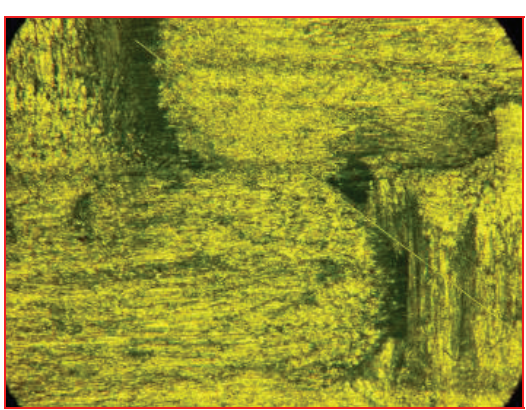

(b)

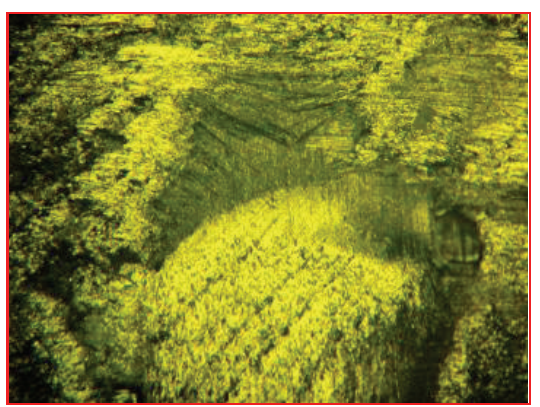

(c)

FIGURE 22: Images by microscope related to surface machined for a cutting depth of (a) $3 \mathrm{~mm}$, (b) $2 \mathrm{~mm}$, and (c) $1 \mathrm{~mm}$.

\section{Results and Discussion: Surface Analysis}

The surface quality has been analyzed by measurements of surface roughness and optical microscopic observations. Roughness measurements have been carried out according to the direction perpendicular to the feed direction; 5 measures of roughness for each machined surface have been acquired. Figures 20-21 show the average roughness measured on each surface according to the axial cutting depth for the three levels of the cut speed and for two levels of feed tooth $(0.022 \mathrm{~mm}$ and $0.044 \mathrm{~mm}$ ); the maximum standard deviation is equal to $7 \%$. Figure 20, relating to a feed tooth of $0.022 \mathrm{~mm}$, shows that the roughness increases with the increase of axial cutting depth and decreases with the increase of the cutting speed in agreement with what has been shown for the components of the cutting force. Figure 21, relating to a feed tooth of $0.044 \mathrm{~mm}$, shows an increased roughness compared to that obtained for the advancement of $0.022 \mathrm{~mm}$.

Preliminary analysis of the surface by LAICA microscope (magnification 50x) shows the presence of defects highlighted as fiber breakage. Figures 22(a), 22(b), and 22(c) show the machined surface related to tests carried out, respectively, with a cutting depth of $3 \mathrm{~mm}, 2 \mathrm{~mm}$, and $1 \mathrm{~mm}$, but cutting speed of $100 \mathrm{~m} / \mathrm{min}$ and feed of $0.022 \mathrm{~mm}$; in Figure 22(a) it is possible to note the presence of surface defects greater than those reported in Figures 22(b) and 22(c).

\section{Conclusion}

In the present work the cutting force components and the surface roughness in CFRP milling have been analyzed. In particular the cutting force radial and tangential components in relation to contact angle and to principal process parameters have been determined. The analysis of results has underlined that the feed speed, depth of cut, and chip thickness significantly influence force components $F_{T}$ and $F_{R}$. An increase of both the cut depth and the chip thickness causes an increase of the force components. Regression analysis has allowed defining the cutting models to predict the cutting force components as function of principal process parameters.

As regards surface roughness it has been possible to value the trend of parameter Ra; the optimal condition has been obtained in correspondence with low axial cutting depth and high cutting speed.

\section{Nomenclature}

$p_{a}:$ Axial cutting depth $[\mathrm{mm}]$

$p_{r}:$ Radial cutting depth $[\mathrm{mm}]$

$t_{\theta}:$ Chip thickness [mm]

$\theta: \quad$ Contact angle [degree]

$v_{t}:$ Cutting speed $[\mathrm{m} / \mathrm{min}]$

$f_{t}:$ Feed per tooth $[\mathrm{mm}]$

$F_{X}$ : Cutting force component along $X$ direction $[\mathrm{N}]$

$F_{Y}$ : Cutting force component along $Y$ direction $[\mathrm{N}]$

$F_{Z}$ : Cutting force component along $Z$ direction $[\mathrm{N}]$

$F_{T}$ : Tangential cutting force $[\mathrm{N}]$

$F_{R}$ : Radial cutting force $[\mathrm{N}]$.

\section{Conflict of Interests}

The authors declare that there is no conflict of interests regarding the publication of this paper.

\section{Acknowledgments}

The authors acknowledge AgustaWestland, Anagni Plant, for providing the CFRP composite material used in the experimental tests. Special thanks are due to Tiziana S.

\section{References}

[1] S. Jahanmir, M. Ramulu, and P. Koshy, Machining of Ceramics and Composites, Marcel Dekker, New York, NY, USA, 2000.

[2] W. F. Smith, Principles of Materials Science and Engineering, McGraw-Hill, New York, NY, USA, 1990.

[3] M. Ramulu, C. W. Wern, and J. L. Garbini, "Effect of fibre direction on surface roughness measurements of machined graphite/epoxy composite," Composites Manufacturing, vol. 4, no. 1, pp. 39-51, 1993.

[4] E. Eriksen, "Influence from production parameters on the surface roughness of a machined short fibre reinforced thermoplastic," International Journal of Machine Tools and Manufacture, vol. 39, no. 10, pp. 1611-1618, 1999. 
[5] P. S. Sreejith, R. Krishnamurthy, S. K. Malhotra, and K. Narayanasamy, "Evaluation of PCD tool performance during machining of carbon/phenolic ablative composites," Journal of Materials Processing Technology, vol. 104, no. 1, pp. 53-58, 2000.

[6] G. C. Everstine and T. G. Rogers, "A theory of machining of reinforced materials," Journal of Composite Materials, vol. 5, pp. 94-106, 1971.

[7] A. Koplev, A. Lystrup, and T. Vorm, "The cutting process, chips, and cutting forces in machining CFRP," Composites, vol. 14, no. 4, pp. 371-376, 1983.

[8] T. Kaneeda, "CFRP cutting mechanism," in Proceedings of the 16th North American Manufacturing Research Conference, pp. 216-221, 1989.

[9] H. Y. Puw and H. Hocheng, "Anisotropic chip formation models of cutting of FRP," in Proceedings of the ASME Symposium on Material Removal and Surface Modification Issues in Machining Processes, New York, NY, USA, 1995.

[10] G. Santhanakrishnan, R. Krishnamurthy, and S. K. Malhotra, "Machinability characteristics of fibre reinforced plastics composites," Journal of Mechanical Working Technology, vol. 17, pp. 195-204, 1988.

[11] M. Ramulu, D. Arola, and K. Colligan, "Preliminary investigation of effects on the surface integrity of fiber reinforced plastics, PD-Vol-64-2," Engineering Systems Design and Analysis, ASME, vol. 2, pp. 93-101, 1994.

[12] H. Hocheng, H. Y. Puw, and Y. Huang, "Preliminary study on milling of unidirectional carbon fibre-reinforced plastics," Composites Manufacturing, vol. 4, no. 2, pp. 103-108, 1993.

[13] W. Hintze Wolfgang, D. Hartmann, and C. Schütte, "Occurrence and propagation of delamination during the machining of carbon fibre reinforced plastics (CFRPs) - an experimental study," Composites Science and Technology, vol. 71, no. 15, pp. 1719-1726, 2011.

[14] D. Liu, Y. Tang, and W. L. Cong, "A review of mechanical drilling for composite laminates," Composite Structures, vol. 94, no. 4, pp. 1265-1279, 2012.

[15] E. U. Enemuoh, A. S. El-Gizawy, and A. C. Okafor, "An approach for development of damage-free drilling of carbon fiber reinforced thermosets," International Journal of Machine Tools and Manufacture, vol. 41, no. 12, pp. 1795-1814, 2001.

[16] J. P. Davim, P. Reis, and C. C. António, "Experimental study of drilling glass fiber reinforced plastics (GFRP) manufactured by hand lay-up," Composites Science and Technology, vol. 64, no. 2, pp. 289-297, 2004.

[17] J. Sheikh-Ahmad, J. Twomey, D. Kalla, and P. Lodhia, "Multiple regression and committee neural network force prediction models in milling FRP," Machining Science and Technology, vol. 11, no. 3, pp. 391-412, 2007.

[18] D. Kalla, J. Sheikh-Ahmad, and J. Twomey, "Prediction of cutting forces in helical end milling fiber reinforced polymers," International Journal of Machine Tools and Manufacture, vol. 50, no. 10, pp. 882-891, 2010.

[19] T. Yashiro, T. Ogawa, and H. Sasahara, “Temperature measurement of cutting tool and machined surface layer in milling of CFRP," International Journal of Machine Tools \& Manufacture, vol. 70, pp. 63-69, 2013.

[20] J. Liu, G. Chen, C. Ji, X. Qin, H. Li, and C. Ren, "An investigation of workpiece temperature variation of helical milling for carbon fiber reinforced plastics (CFRP)," International Journal of Machine Tools and Manufacture, vol. 86, pp. 89-103, 2014.
[21] S. Turchetta, "Cutting force on a diamond grit in stone machining," International Journal of Advanced Manufacturing Technology, vol. 44, no. 9-10, pp. 854-861, 2009.

[22] S. Turchetta, "Cutting force and diamond tool wear in stone machining," International Journal of Advanced Manufacturing Technology, vol. 61, no. 5-8, pp. 441-448, 2012. 

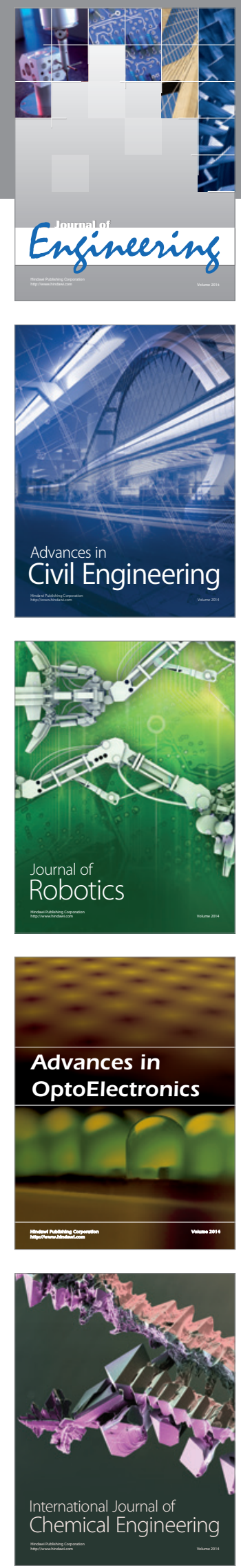

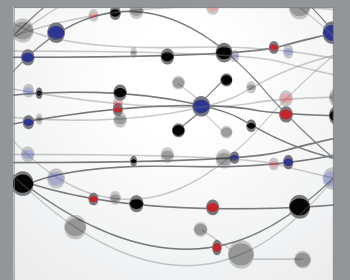

The Scientific World Journal
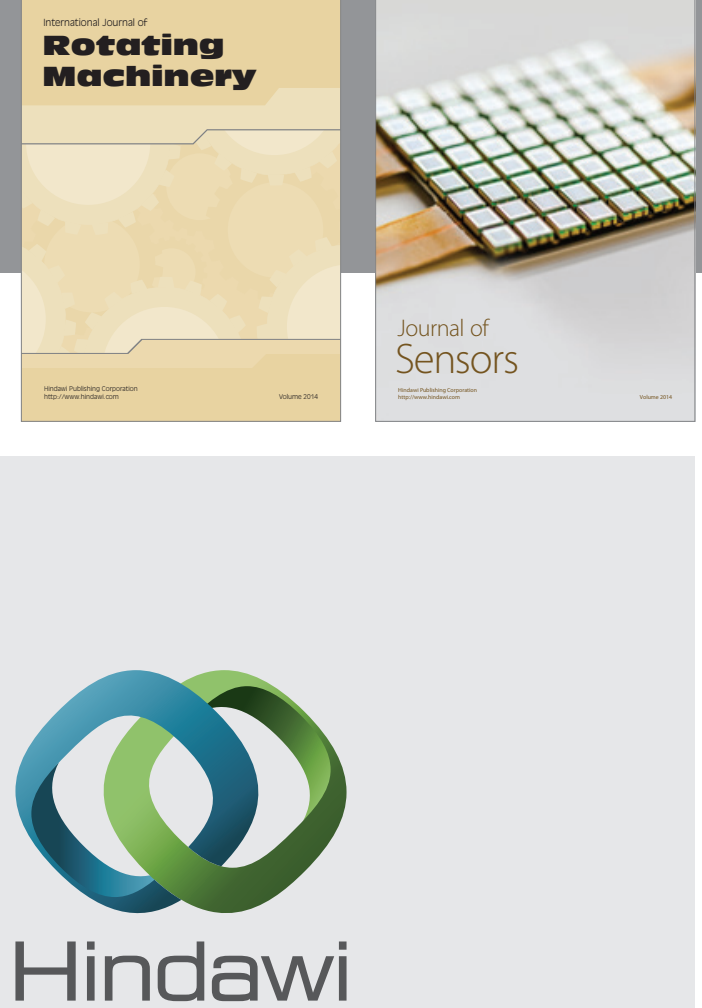

Submit your manuscripts at http://www.hindawi.com
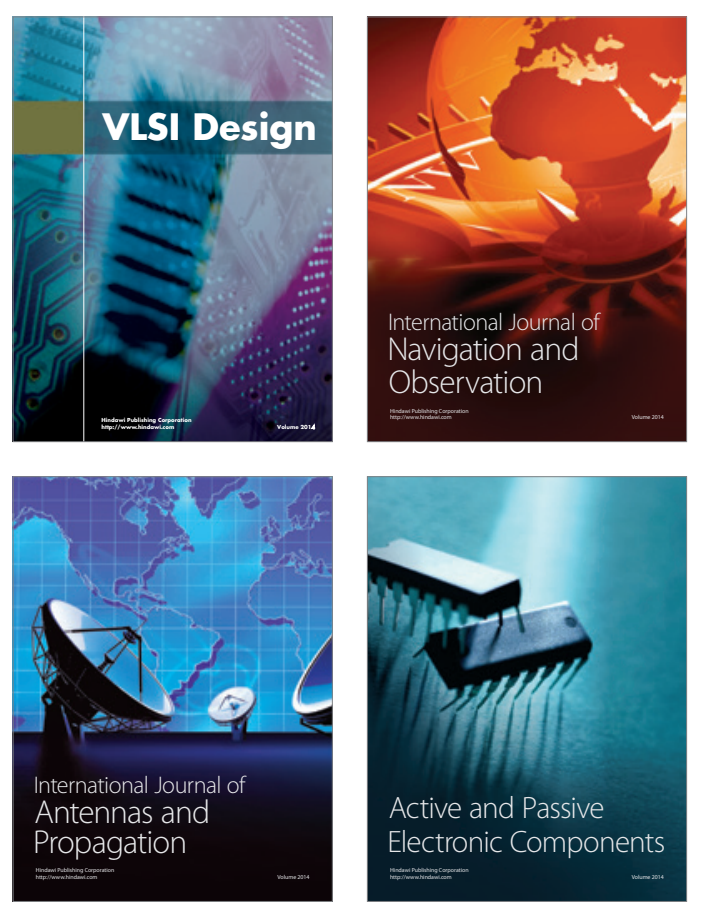
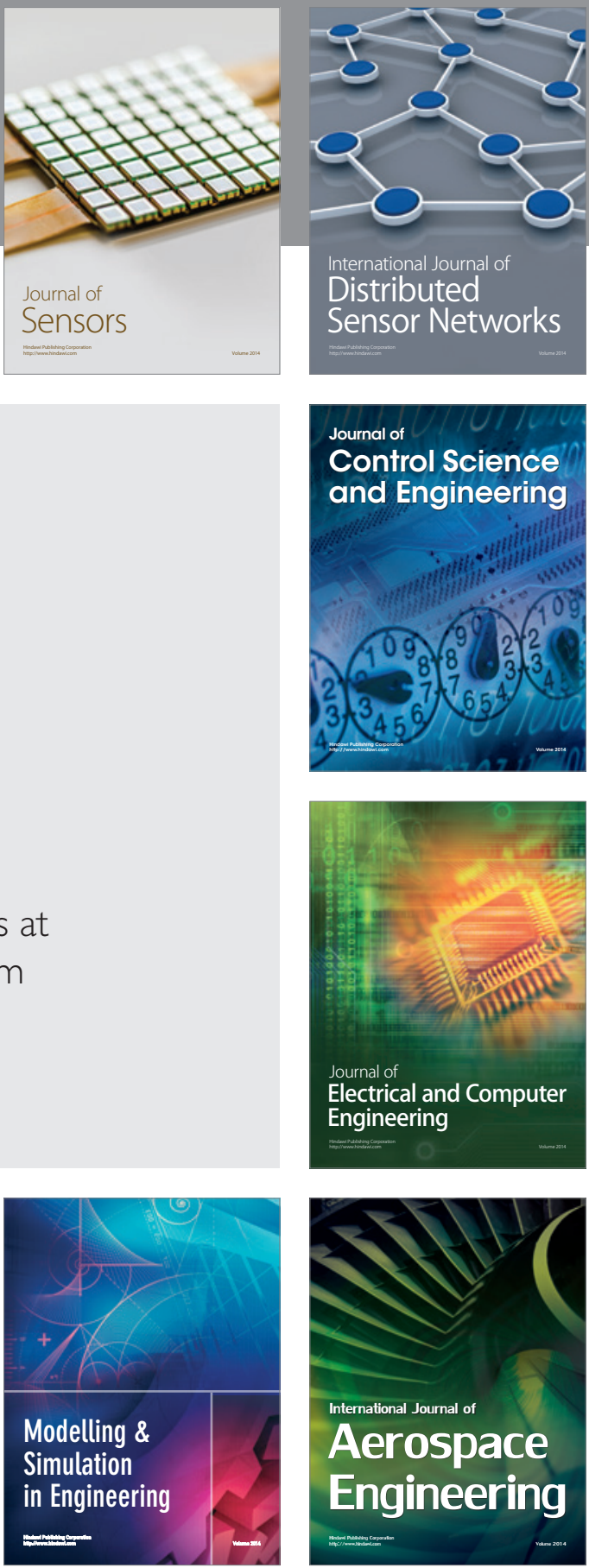

Journal of

Control Science

and Engineering
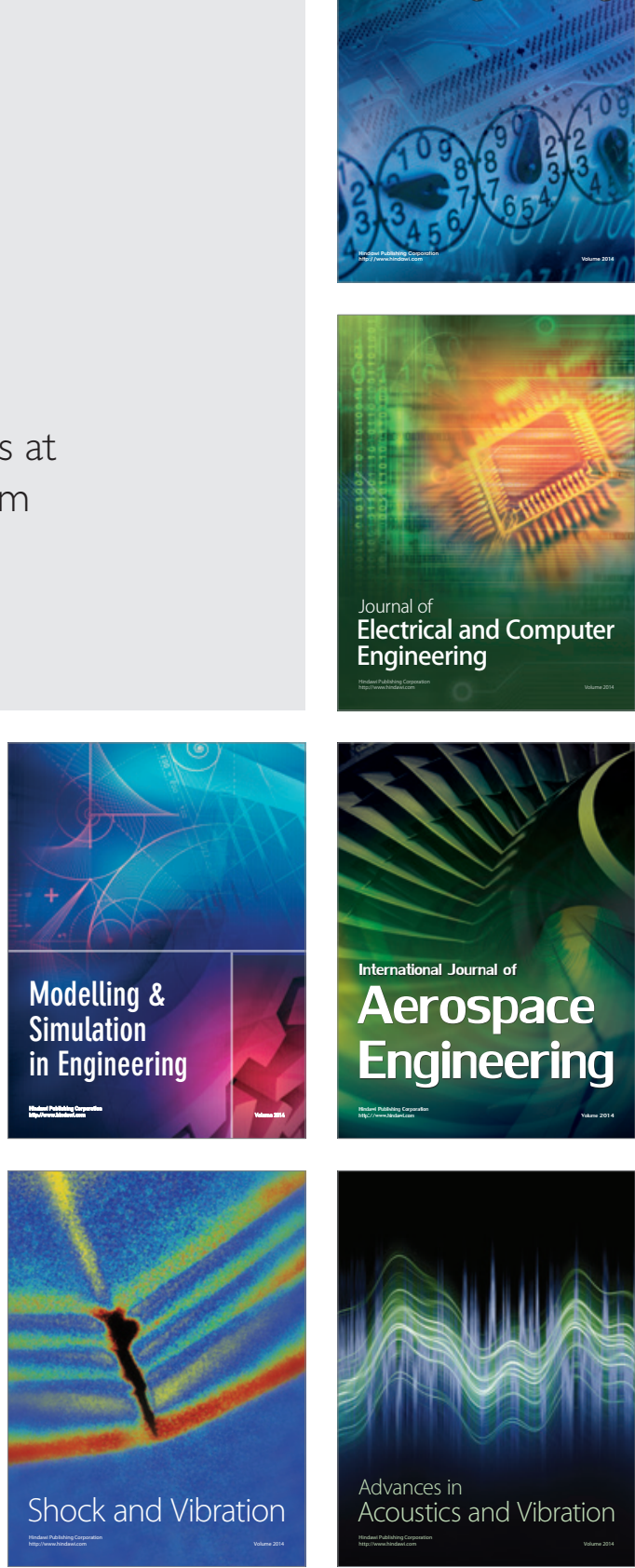